\title{
Peculiarities of luminescence and scintillation properties of YAP:Ce and LuAP:Ce single crystals and single crystalline films
}

\author{
Y. Zorenko ${ }^{\mathrm{a}, *}$, V. Gorbenko ${ }^{\mathrm{a}}$, I. Konstankevych ${ }^{\mathrm{a}}$, T. Voznjak ${ }^{\mathrm{a}}$, V. Savchyn ${ }^{\mathrm{a}}$, M. Nik1 ${ }^{\mathrm{b}}$, J.A. Mares ${ }^{\mathrm{b}}$, \\ K. Nejezchleb ${ }^{\mathrm{c}}$, V. Mikhailin ${ }^{\mathrm{d}}$, V. Kolobanov $^{\mathrm{d}}$, D. Spassky ${ }^{\mathrm{d}}$ \\ ${ }^{a}$ Laboratory of Optoelectronic materials (LOM), Department of Electronic, Ivan Franko National University of Lviv, 79017 Lviv, Ukraine \\ ${ }^{\mathrm{b}}$ Institute of Physics AS CR, Cukrovarnicka 10, 16253 Prague, Czech Republic \\ ${ }^{\mathrm{c}}$ Crytur Ltd, Palackeho 175, 51119 Turnov, Czech Republic \\ d Physical Faculty, Moscow State University, 119899 Moscow, Russia
}

Received 17 December 2006; accepted 31 January 2007

\begin{abstract}
Luminescent properties and the energy transfer from host to $\mathrm{Ce}^{3+}$ ions are analyzed in single crystalline films $(\mathrm{SCF})$ of $\mathrm{YAlO}_{3}: \mathrm{Ce}(\mathrm{YAP}: \mathrm{Ce})$, $\mathrm{Y}_{1-x} \mathrm{Lu}_{x} \mathrm{AP}: \mathrm{Ce}$ (YLuAP:Ce) and $\mathrm{LuAlO}_{3}: \mathrm{Ce}$ (LuAP:Ce) perovskites in comparison with their single crystal (SC) analogues using the timeresolved luminescence spectroscopy under synchrotron radiation excitation. It is shown that the main peculiarity of luminescent properties of YAP:Ce, YLuAP:Ce and LuAG:Ce SCF is determined by the extremely low concentration of $\mathrm{Y}_{\mathrm{Al}}$ and Lu $\mathrm{Ll}_{\mathrm{Al}}$ antisite defects and vacancy-type defects in SCF as compared to SC. The advantages of phosphors based on (Y-Lu)AP:Ce SCF are due to the absence of emission and trapping centers in these SCF which are connected with the above mentioned bulk crystal defects.
\end{abstract}

(C) 2007 Published by Elsevier Ltd.

Keywords: Perovskites; Single crystal and single crystalline films; $\mathrm{Ce}^{3+}$ ions; Scintillators; Luminescence

\section{Introduction}

Ce-doped $\mathrm{YAlO}_{3}$ (YAP) and $\mathrm{LuAlO}_{3}$ (LuAP) perovskites are efficient high-response scintillators for medical application (Lempicki et al., 1995; Nikl, 2000). Due to high melting temperatures, low oxygen pressure in growth atmosphere, existence of two cation sublattice and cations of the equal charge state, a variety of point defects exists in single crystal (SC) of perovskites (Stanek et al., 2006). Among them, the $\mathrm{Y}_{\mathrm{Al}}$ and $\mathrm{Lu}_{\mathrm{Al}}$ antisite defects $(\mathrm{AD})$ and vacancy-type defects $(\mathrm{VD})$ are of particular importance for their scintillation performance (Nikl, 2005, Zorenko et al., 2004a). AD and VD can often create parent sites for electron or hole capture which usually degrade light yield (LY) and timing characteristics of the scintillators (Nikl et al., 2005, Vedda et al., 2000, 2006).

For some other applications the high-density single crystalline film (SCF) scintillators are developed (Koch et al., 1998,

\footnotetext{
* Corresponding author.

E-mail address: zorenko@electronics.wups.lviv.ua (Y. Zorenko).
}

1999; Zorenko et al., 2002, 2005b). The SCF grown from meltsolution (MS) at low $\left(<1000^{\circ} \mathrm{C}\right)$ temperatures in air are characterized by the absence of $\mathrm{AD}$ and by extremely low concentrations of VD as compared with the SC analogues (Zorenko et al., 2004a; 2007a,b). Therefore, we expect that the scintillators based on SCF of perovskites will have better spectralkinetic characteristics with respect to their SC analogues due to the absence of the emission and trapping centers connected with $\mathrm{AD}$ and VD.

The aim of this work was investigation of the time-resolved luminescence of YAP:Ce, YLuAP:Ce and LuAP:Ce SCF in comparison with their bulk SC analogues, as well as the peculiarities of energy transfer to $\mathrm{Ce}^{3+}$ ions in the SC and SCF under the synchrotron radiation (SR) excitation.

\section{Samples and experimental technique}

YAP:Ce and $\mathrm{Lu}_{0.3} \mathrm{Y}_{0.7} \mathrm{AP}: \mathrm{Ce}$ (LuYAP:Ce) SC were grown by Crytur (Czech Republic) from melt by the Czochralski 
method from a Mo crucible in reducing atmosphere using the charge containing $\mathrm{Y}_{2} \mathrm{O}_{3}, \mathrm{Lu}_{2} \mathrm{O}_{3}, \mathrm{CeO}_{2}$ (5 N purity) and $\mathrm{Al}_{2} \mathrm{O}_{3}$ ( $4 \mathrm{~N}$ purity) oxides. The content of $\mathrm{Ce}$ ions in the mentioned SC was 0.09 and 0.19 at\%, respectively. The sample of YAP:Ce $\mathrm{SC}$ with low $\mathrm{Ce}^{3+}$ content (a few tens ppm) was also studied for comparison. The Ce-doped YAP, $\mathrm{Lu}_{0.6} \mathrm{Y}_{0.4} \mathrm{AP}$ :Ce and $\mathrm{LuAP}$ SCF were grown by the liquid phase epitaxy in the LOM Lviv University (Ukraine) from the MS based on $\mathrm{PbO}-\mathrm{B}_{2} \mathrm{O}_{3}$ flux and crystal-forming oxides of the same purity on the substrates of undoped YAP SC. The optimal content of $\mathrm{CeO}_{2}$ oxide in the MS (10-13 mol\%) was chosen experimentally and corresponds to the maximum LY of SCF scintillators under excitation by $\alpha$-particles of $\mathrm{Pu}^{239}$ sources $(5.5 \mathrm{MeV})$.

The time-resolved luminescence of YAP:Ce, LuAP:Ce and LuYAP:Ce SC and SCF at 9-300 K were investigated at the Superlumi station in HASYLAB at DESY, Hamburg under excitation by SR with an energy of $3.7-25 \mathrm{eV}$. The emission and excitation spectra were measured both in the integral regime and in time gates of 1.2-11 ns (fast component) and 150-200 ns (slow component) in the limits of SR pulse with a repetition time of $200 \mathrm{~ns}$ and a duration of $0.127 \mathrm{~ns}$. The decay kinetics of luminescence was measured in a time range of $1.2-200 \mathrm{~ns}$ at $300 \mathrm{~K}$.

\section{Luminescence of SCF and SC of perovskites}

The luminescence spectra of YAP:Ce SC with low $\mathrm{Ce}^{3+}$ content (a few tens ppm) at 9-220 K under excitation by SR with an energy of $7.835 \mathrm{eV}$ in the exciton range at $9 \mathrm{~K}$ (curve 1) and $180 \mathrm{~K}$ (curve 2) are shown in Fig. 1. The typical 5d $>4$ f luminescence of $\mathrm{Ce}^{3+}$ ion in the doublet bands at 350 and $375 \mathrm{~nm}$ as well as the two bands of host emission peaked at 218 and $302 \mathrm{~nm}$ are observed in the spectra of this YAP:Ce SC. The 218 and $302 \mathrm{~nm}$ bands are related to the luminescence of excitons localized around AD and VD (LE (AD) and LE (VD) bands,

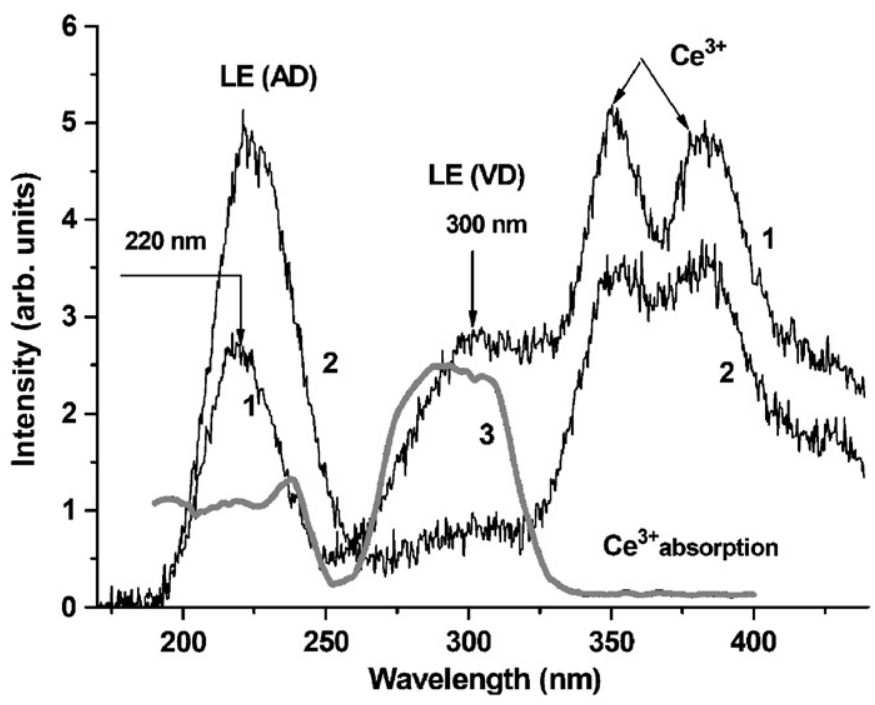

Fig. 1. Emission spectra of the YAP:Ce ( $\sim$ few tens ppm) SC at $9 \mathrm{~K}$ (1) and $180 \mathrm{~K}(2)$ under excitation by SR with an energy of $7.835 \mathrm{eV}$ in the exciton range. Absorption spectrum of YAP:Ce SC (3) is shown for comparison. respectively) (Zorenko et al., 2004a; 2007a). It is worth noting that the host emission bands at 218 and $302 \mathrm{~nm}$ in YAP:Ce SC are strongly overlapped with the $\mathrm{Ce}^{3+}$ absorption bands peaked at 219 and $239 \mathrm{~nm}$ and around $300 \mathrm{~nm}$, respectively (Fig. 1, curve 3). As a result of the such overlap, the $\mathrm{Ce}^{3+}$ emission in YAP:Ce and LuYAG:Ce SC is partly excited via the host emission.

The time-resolved emission spectra of YAP:Ce and LuYAP:Ce SC and SCF at $300 \mathrm{~K}$ measured in the integral (1), fast (2) and slow (2) time gates under excitation by SR in the region of interband transition are presented in Fig. 2. The wide complex bands peaked at $360-365 \mathrm{~nm}$ range related to the $5 \mathrm{~d}>4 \mathrm{f}$ transition of $\mathrm{Ce}^{3+}$ ions are observed in the spectra of all SC and SCF. From the data presented in the Fig. 2 it can be noted that the characteristics features of the $\mathrm{Ce}^{3+}$ emission in the YAP:Ce and LuYAP:Ce SC and SCF are as follows: (i) significantly large $(\sim 20$ times) intensity of slow components in $\mathrm{Lu}_{0.3} \mathrm{Y}_{0.7} \mathrm{AP}: \mathrm{Ce} \mathrm{SC}$ in comparison with the YAP:Ce SC (Fig. 2(a)-(c), respectively, curves 3); (ii) notable lower intensity of the slow components and large intensity of fast components in spectra of YAP:Ce and $\mathrm{Lu}_{0.4} \mathrm{Y}_{0.6} \mathrm{AP}: \mathrm{Ce} \mathrm{SCF}$ with respect to bulk SC analogues (Fig. 2(a),(b) and (c),(d), respectively, curves 3).

Excitation spectra of the $\mathrm{Ce}^{3+}$ luminescence in YAP:Ce SC (a) and SCF (b) and $\mathrm{Lu}_{1-x} \mathrm{Y}_{x} \mathrm{AP}: \mathrm{Ce} \mathrm{SC}$ (c) and SCF (d) at $300 \mathrm{~K}$ are shown in Fig. 3. The spectra of all SC and SCF contain three main bands in the $305-275 \mathrm{~nm}$ region and two weaker bands in $232-215 \mathrm{~nm}$ range corresponding to the transitions

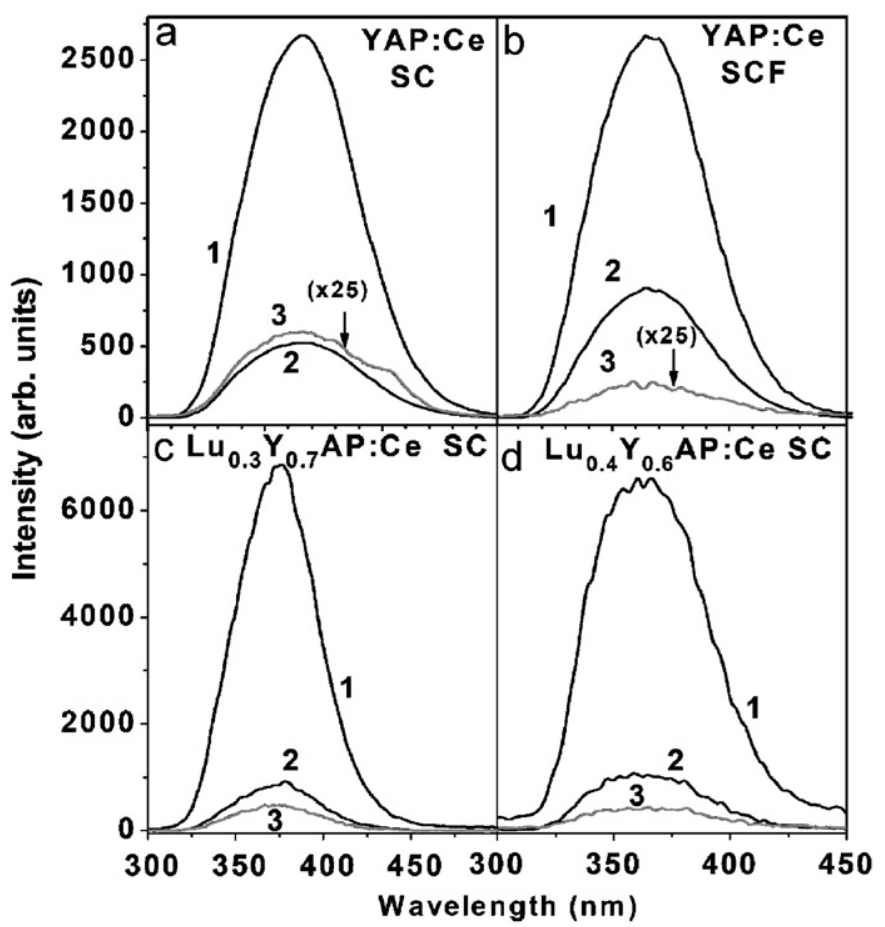

Fig. 2. Spectra of the integral (1), fast (2) and slow (3) emission components in YAP:Ce SC (a) and SCF (b), $\mathrm{Lu}_{0.3} \mathrm{Y}_{0.7} \mathrm{AP}: \mathrm{Ce} \mathrm{SC}$ (c) and $\mathrm{Lu}_{0.6} \mathrm{Y}_{0.4} \mathrm{AP}: \mathrm{Ce}$ SCF (d) at $300 \mathrm{~K}$ under excitation by SR with an energy of $14.6 \mathrm{eV}$ (a), (b) and $11.3 \mathrm{eV}(\mathrm{c}),(\mathrm{d})$, normalized to the maxima intensity of $\mathrm{Ce}^{3+}$ emission band in the integral spectra. 

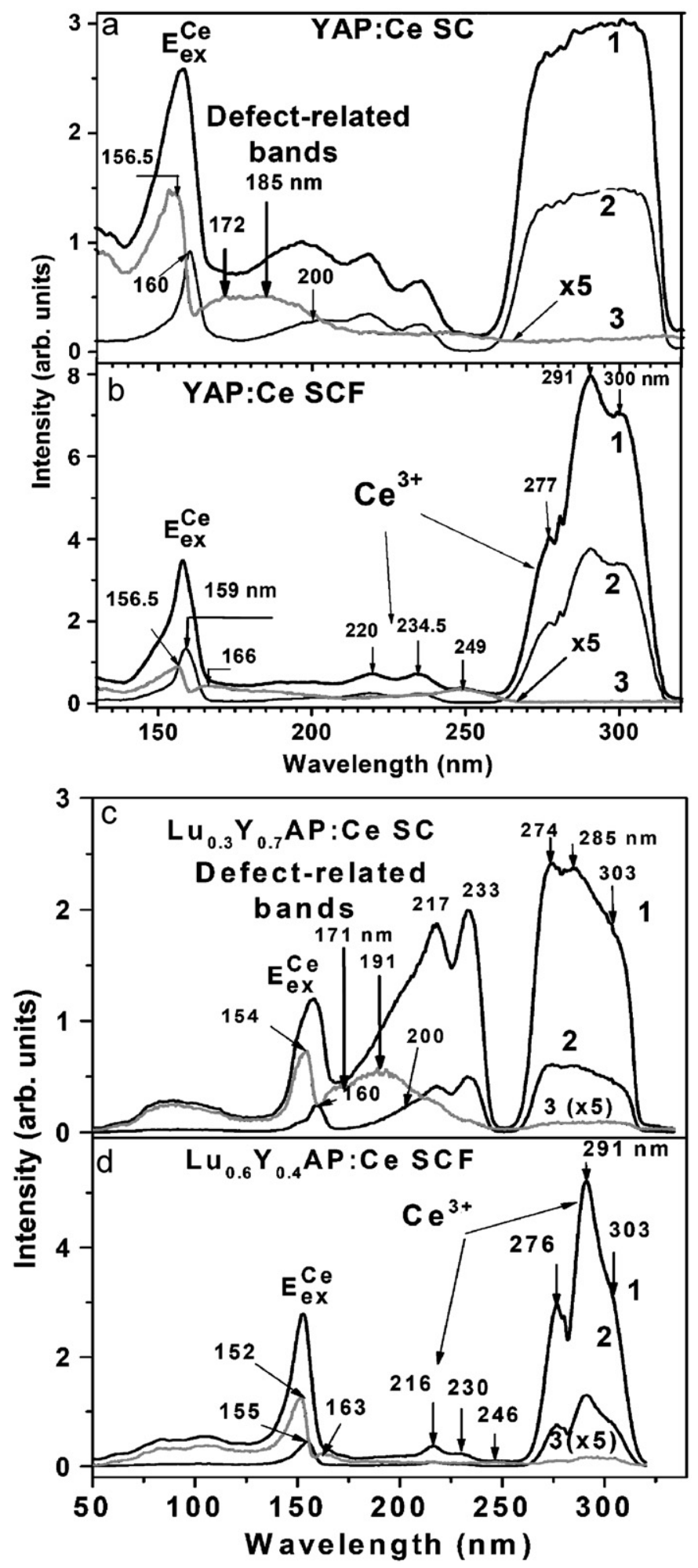

Fig. 3. Excitation spectra of the integral (1), fast (2) and slow (3) components of $\mathrm{Ce}^{3+}$ luminescence in YAP:Ce SC (a) and SCF (b) and $\mathrm{Lu}_{1-x} \mathrm{Y}_{x} \mathrm{AP}: \mathrm{Ce}$ $\mathrm{SC}$ (c) and SCF (d) at $9 \mathrm{~K}$.

between the $4 f\left({ }^{2} \mathrm{~F}_{5 / 2}\right)$ level of ground state to the $5 \mathrm{~d}\left({ }^{3} \mathrm{~T}_{2}\right)$ and $5 \mathrm{~d}\left({ }^{2} \mathrm{E}\right) 5 \mathrm{~d}(2 \mathrm{e})$ levels of $\mathrm{Ce}^{3+}$ ions, respectively. In addition to these bands, the excitation spectra of the fast components of Ce emission in YAP:Ce and $\mathrm{Lu}_{1-x} \mathrm{Y}_{x} \mathrm{AP}: \mathrm{Ce} \mathrm{SC}$ and SCF also show a wide band at $200 \mathrm{~nm}$ most probably caused by the $4 \mathrm{f} \rightarrow 6 \mathrm{~s}$ transitions of $\mathrm{Ce}^{3+}$ ions (Wojtowicz et al., 2002). The excitation of the fast and slow components of Ce emission in $\mathrm{Lu}_{1-x} \mathrm{Y}_{x} \mathrm{AP}: \mathrm{Ce} \mathrm{SCF}$ and SC in the exciton range (Fig. 3, curves 2) at $9 \mathrm{~K}$ occurs in the narrow bands peaked correspondingly in 159-155 $\mathrm{nm}$ and $156.5-152 \mathrm{~nm}$ ranges. The existence of the two excitation maxima of the Ce emission in $\mathrm{Lu}_{1-x} \mathrm{Y}_{x} \mathrm{AP}: \mathrm{Ce}$ SCF and SC indicates that the excited state of an exciton bound with the $\mathrm{Ce}^{3+}$ ions probably has two radiative levels.

The low-intensive excitation bands at 166 and $249 \mathrm{~nm}$ for YAP:Ce SCF or 163 and $246 \mathrm{~nm}$ for $\mathrm{Lu}_{0.6} \mathrm{Y}_{0.4} \mathrm{AP}: \mathrm{Ce} \mathrm{SCF}$ occur only in the SCF. Most probably, these bands are caused by the $\mathrm{Pb}^{2+}$ impurity, coming in the SCF from the PbO-based flux, and corresponds to the excitation of excitons bound with the $\mathrm{Pb}^{2+}$ ions and with the ${ }^{1} \mathrm{~S}_{0} \rightarrow{ }^{3} \mathrm{P}_{1}$ transition of $\mathrm{Pb}^{2+}$ ions, respectively (Babin et al., 2007).

It is worth noting that the Ce emission in $\mathrm{SC}$ is also excited in the bands peaked at 172 and $186 \mathrm{~nm}$ for YAP:Ce SC or at 171 and $191 \mathrm{~nm}$ for $\mathrm{Lu}_{0.3} \mathrm{Y}_{0.7} \mathrm{AP}: \mathrm{Ce} \mathrm{SC}$ (Fig. 3(a) and (c), respectively) which are apparently related to the intrinsic lattice defects of YAP and LuYAP SC (Wojtowicz et al., 2002). The most prominent feature of the excitation spectra of YAP:Ce and LuAP:Ce SCF with respect to SC analogues is noticeably lower intensity of the defect-related excitation bands peaked at 171-172 nm and 185-191 nm (Fig. 3(b) and (c), respectively), what points to the considerably lower concentrations of these defects in SCF in comparison with YAP:Ce SC.

This statement is confirmed by an essential difference in the decay kinetics of $\mathrm{Ce}^{3+}$ emission in $\mathrm{Lu}_{1-x} \mathrm{Y}_{x} \mathrm{AP}: \mathrm{Ce} \mathrm{SC}$ and SCF (Fig. 4(a) and (b), respectively). Under excitation in the $\mathrm{Ce}^{3+}$ absorption bands in the 275-300 nm range, the decay curves for YAP:Ce and LuAP:Ce SC and SCF coincides with lifetimes of emission of 16.2 and $15.4 \mathrm{~ns}$, respectively (Fig. 4(a) and (b), curves 1 and 2). At the same time, under excitation in the region of interband transitions $\left(75-85 \mathrm{~nm}, E>2 E_{g}\right.$ ), the decay kinetic of Ce emission for SCF and SC are noticeably different; specifically, the YAP:Ce and $\mathrm{Lu}_{0.6} \mathrm{Y}_{0.4} \mathrm{AP}: \mathrm{Ce}$ SCF demonstrate the notably faster decay kinetics than their SC analogues (Fig. 4(a) and (b), curves 3 and 4, respectively). Corresponding average decay times of Ce emission at $300 \mathrm{~K}$ are equal to 27.8 and $38.6 \mathrm{~ns}$ for YAP:Ce SCF and SC, $19.6 \mathrm{~ns}$ for $\mathrm{Lu}_{0.6} \mathrm{Y}_{0.4} \mathrm{AP}: \mathrm{Ce} \mathrm{SCF}$ and $24.3 \mathrm{~ns}$ for $\mathrm{Lu}_{0.3} \mathrm{Y}_{0.7} \mathrm{AP}: \mathrm{Ce} \mathrm{SC}$, respectively, at the same excitation wavelengths.

For estimation of the slow components content in the scintillation decay we used the ratio between the intensity $I_{\mathrm{s}}$ of decay components which are slower than the repetition frequency of SR and intensity $I(t)$ of rising part of the scintillation pulse as $K_{\mathrm{S}}=\left[I_{\mathrm{S}} / I(t)\right] * 100 \%$ (Fig. 4). For YAP:Ce SC and SCF the $K_{\mathrm{S}}=0.74 \%$ and $0.07 \%$ values, respectively, was obtained (Fig. 4, curves 3 and 4) under high-energy excitation (16.5 eV). Thus, in the YAP:Ce SC the content of the slow components in the scintillation decay is higher by one order of value with respect to SCF (Table 1) that reflects significant participation of $\mathrm{AD}$ and $\mathrm{VD}$ in the delivery of excitation energy to the $\mathrm{Ce}^{3}$ ions. For LuYAP:Ce SC and SCF the noticeably large values of $K_{\mathrm{S}}=4.1 \%$ and $2.9 \%$ as compared to YAP:Ce SC and SCF were obtained (Fig. 4(b), curves 3 and 4, respectively). 

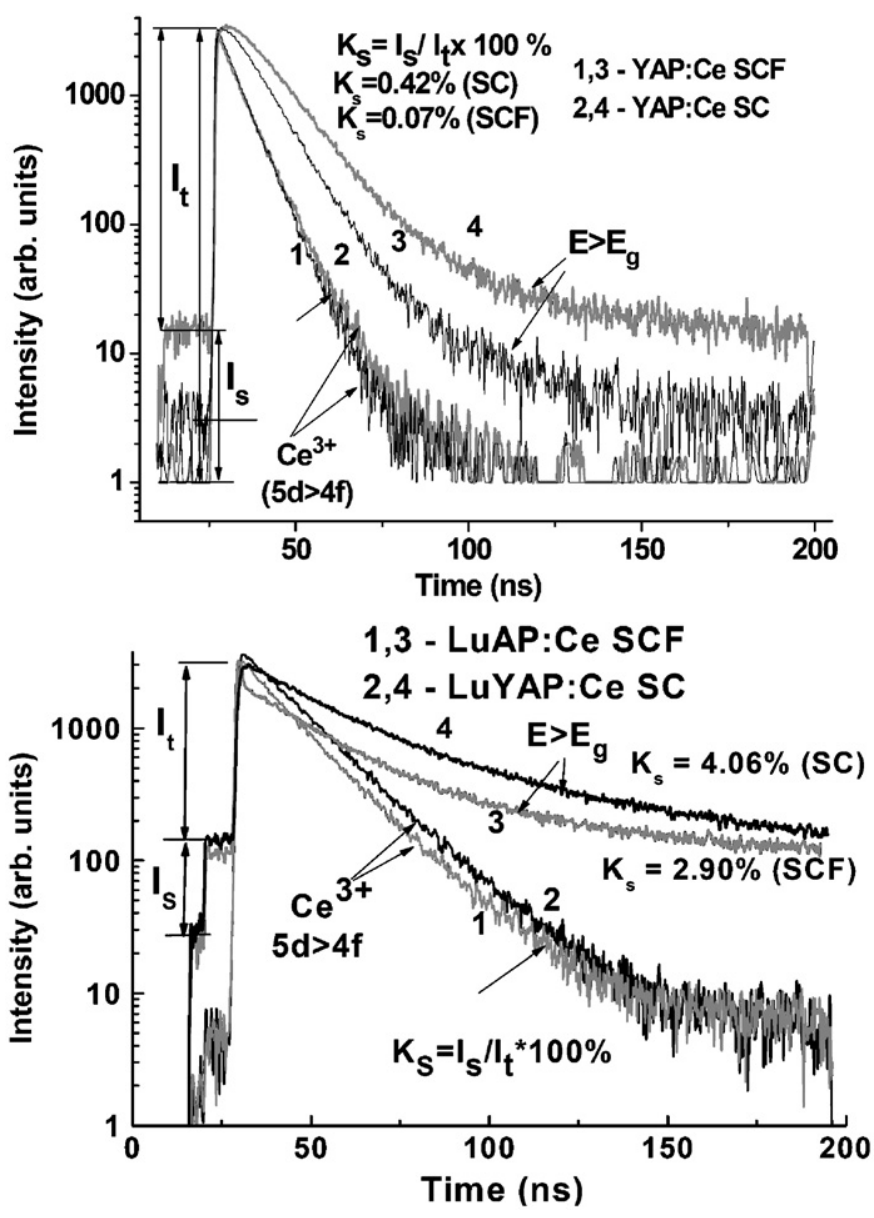

Fig. 4. Decay kinetics of Ce emission at $300 \mathrm{~K}$ in YAP:Ce (a) SCF $(1,3)$ and SC $(2,4), \operatorname{Lu}_{0.6} \mathrm{Y}_{0.4} \mathrm{AP}: \mathrm{Ce}(\mathrm{b}) \mathrm{SCF}(1,3)$ and $\mathrm{Lu}_{0.3} \mathrm{Y}_{0.6} \mathrm{AP}: \mathrm{Ce}$ (b) SC $(2,4)$ excited by SR in the region of interband transitions $(75-85 \mathrm{~nm})(1,2)$ and $\mathrm{Ce}^{3+}$ absorption band at $280 \mathrm{~nm}(3,4)$.

Table 1

Comparison of the content of slow components for SC and SCF of garnets and perovskites

\begin{tabular}{ll}
\hline Scintillators & Content of slow components, Ks, \% \\
\hline LuAP:Ce SC & 4.06 \\
LuAP:Ce SCF & 2.9 \\
YAP:Ce SC & 0.42 \\
YAP:Ce SCF & 0.07 \\
YAG:Ce SC & 6.3 (Zorenko et al., 2007a,b) \\
LuAG:Ce SC & 74.5 (Zorenko et al., 2007a,b) \\
\hline
\end{tabular}

The largest value of $K_{\mathrm{S}}$ for LuYAP:Ce SC with respect to YAP:Ce SC (Table 1) probably is caused by the highest concentration of $\mathrm{AD}$ in Lu-based perovskites. It is worth noting that this result is coherent with the previous theoretical calculation of the AD concentration in perovskites (Stanek et al., 2006). In this work it was shown that the $\mathrm{Lu}_{\mathrm{Al}} \mathrm{AD}$ have lower energy of formation in comparison with $\mathrm{Y}_{\mathrm{Al}} \mathrm{AD}$ what can result in larger concentration of AD in LuAP SC.

Notable difference in $K_{\mathrm{S}}$ values between the LuYAP:Ce SCF and YAP:Ce SCF can be explained by the large contribution of the $\mathrm{Pb}^{2+}$ ions emission with the lifetimes of fast and slow components in ns and $\mu$ s ranges, respectively, in the $\mathrm{Ce}^{3+} \mathrm{lu}-$ minescence in LuYAP:Ce SCF as a result of overlapping of the corresponding bands peaked around 360-380 nm (Babin et al., 2007). It also explains the atypically faster initial part and slower main part of the decay curve 3 for $\mathrm{Lu}_{0.6} \mathrm{Y}_{0.3} \mathrm{AP}: \mathrm{Ce}$ $\mathrm{SCF}$ as compared with the decay curve 4 for $\mathrm{Lu}_{0.3} \mathrm{Y}_{0.7} \mathrm{AP}: \mathrm{Ce}$ SC (Fig. 4b).

\section{Discussion}

Observed features of the YAP:Ce and LuAP:Ce SC and SCF luminescence can be explained by the different concentration of AD- and VD-related emission and trapping centers in these phosphors. Since the LE (AD) and LE (VD) emission bands at 220 and $300 \mathrm{~nm}$ in SC with typical lifetime in hundred ns range (Zorenko et al., 2004a) considerably overlap the $\mathrm{Ce}^{3+}$ absorption bands at 236 and $219 \mathrm{~nm}$ and around $290 \mathrm{~nm}$, respectively (Fig. 1), the decay kinetics of $\mathrm{Ce}^{3+}$ emission in YAP:Ce and LuYAP:Ce SC possesses the large contribution of slow components resulting from the non-radiative energy transfer between the defect-related centers and $\mathrm{Ce}^{3+}$ ions (Zorenko et al., 2007a,b). Another reason for the slow components presence can be an intermediate temporary localization of charge carriers at AD or VD acting as trapping centers (Nikl et al., 2005; Vedda et al., 2000; 2006). For SC of perovskites as compared to garnet SC (Zorenko et al., 2007a,b) substantially smaller contribution of slow components in scintillation decay is found basing on the value of $K_{\mathrm{S}}$ (Table 1). This might be due to the significant difference in the type and concentration of the host defects for these type oxides, first of all, for the $\mathrm{Y}_{\mathrm{Al}}$ and $\mathrm{Lu}_{\mathrm{Al}} \mathrm{AD}$, which are thus expected in $\mathrm{SC}$ of perovskites with, at least, one order lower concentration.

At the same time, for YAP:Ce and LuYAP:Ce SCF the content of the slow components in the scintillation decay is 1.4-6 times lower compared to SC (Table 1). This reflects the substantially smaller contribution of intrinsic defects in the scintillation decay of SCF phosphors as compared to SC analogs. This finding is consistent with the difference in the excitation spectra of YAP:Ce and LuYAP:Ce SCF with respect to SC (Fig. 2(b) and (a), respectively), which show noticeably lower intensity of the 171-172 and 185-191 nm bands related to the intrinsic lattice defects of YAP and LuYAP SC (Zorenko et al., 2004a). This points to the considerably lower concentrations of these centers in SCF in comparison with YAP:Ce and LuYAP:Ce SC. Due to correlation between the spectral positions of these bands and excitation bands of $\mathrm{F}^{+}$and $\mathrm{F}$ centers emission in the exciton region in YAP SC (Zorenko et al., 2004b; 2005a), the nature of this bands more likely corresponds to the transitions from the oxygen-based levels of the upper part of valence band (VB) perturbed by the $\mathrm{Ce}^{3+}$ ions and levels of the VD-related centers with one or two trapped electrons (e). After localization of the hole (h) coming from the $\mathrm{VB}$ at the $\mathrm{Ce}^{3+}$ ion the formation of closely located $\mathrm{Ce}^{3+}(\mathrm{h})-\mathrm{VD}$ (e or $2 \mathrm{e}$ ) pair centers takes place (Krasnikov et al., 2005, Blazek et al., 2005). Radiative recombination of e-h pair located around such defect/impurity centers can induce slow components in emission of YAP:Ce and LuAP:Ce SC. 


\section{Conclusion}

Unlike the SC analogues, the phosphors based on YAP:Ce, LuYAP:Ce and LuAP:Ce SCF demonstrate the faster decay kinetics of $\mathrm{Ce}^{3+}$ emission and low content of slow components in scintillation decay under high-energy excitation. This is caused by the absence in SCF of YAP:Ce and LuYAP:Ce perovskites the additional channels for dissipation of excitation energy via $\mathrm{AD}$ and VD-related centers.

\section{Acknowledgments}

The authors express their gratitude to Prof. Dr. G. Zimmerer for his assistance in carrying out the experiments in HASYLAB at DESY. The work was supported by INTAS project 04-787083 and Czech GACR project No. 202/05/2471.

\section{References}

Babin, V., Gorbenko, V., Makhov, A., Mares, J.A., Nikl, M., Zazubovich, S., Zorenko, Yu. 2007. Luminescence characteristics of $\mathrm{Pb}^{2+}$ centers in undoped and $\mathrm{Ce}^{3+}$-doped $\mathrm{Lu}_{3} \mathrm{Al}_{5} \mathrm{O}_{12}$ single crystalline films and $\mathrm{Pb}^{2+} \rightarrow \mathrm{Ce}^{3+}$ energy transfer processes, J. Lumin., doi:10.1016/j.jlumin. 2007.01.011.

Blazek, K., Krasnikov, Nejezchleb, K., Nikl, M., Savikhina, S., Zazubovich, S., 2005. Luminescence and defect creation in $\mathrm{Ce}^{3+}$-doped $\mathrm{YAlO}_{3}$ and $\mathrm{Lu}_{0.3} \mathrm{Y}_{0.7} \mathrm{AlO}_{3}$ crystals. Phys. Status. Solidi (b) 242, 1315-1323.

Koch, A., Raven, C., Spanne, P., Snigirev, A., 1998. X-ray imaging with submicrometer resolution employing transparent luminescent screens. J. Opt. Soc. Am. A 15, 1940-1951.

Koch, A., Peyrin, F., Heurtier, P., Chambaz, B., Ferrand, B., Ludwig, W., Couchaud, M., 1999. An X-ray camera for computed microtomography of biological samples with micrometer resolution using $\mathrm{Lu}_{3} \mathrm{Al}_{5} \mathrm{O}_{12}$ and $\mathrm{Y}_{3} \mathrm{Al}_{5} \mathrm{O}_{12}$ scintillators. Proc. SPIE 3659, 170-179.

Krasnikov, A., Savikhina, T., Zazubovich, S., Nikl, M., Mares, J.A., Blazek, K., Nejezchleb, K., 2005. Luminescence and defects creation in $\mathrm{Ce}^{3+}$. doped aluminium and lutetium perovskites and garnets. NIMA 537, 130-133.

Lempicki, A., Randles, M.H., Wisniewski, D., Balcerzyk, M., Brecher, C., Wojtowicz, A.J., 1995. $\mathrm{LuAlO}_{3}-\mathrm{Ce}$ and other aluminate scintillators. IEEE Trans. Nucl. Sci. 42, 280-284.

Nikl, M., 2000. Wide band gap scintillation materials. Progress in the technology and material understanding. Phys. Status. Solidi (a) 178, $595-620$.
Nikl, M., 2005. Energy transfer in the luminescence of wide band-gap scintillators. Phys. Status. Solidi (a) 202, 201-206.

Nikl, M., Mihokova, E., Pejchal, J., Vedda, A., Zorenko, Yu., 2005. The antisite $\mathrm{Lu}_{\mathrm{Al}}$ defect-related trap in $\mathrm{Lu}_{3} \mathrm{Al}_{5} \mathrm{O}_{12}$ : Ce single crystal. Phys. Status. Solidi (b) 242, R119-R121.

Stanek, C.R., Levy, M.R., McClellan, K.J., Grimes, R.W., 2006. Defect behavior in rare earth $\mathrm{REAlO}_{3}$ perovskite scintillators. J. Appl. Phys. 99, $113518,1-7$

Vedda, A., Martini, M., Mienardi, F., Chval, J., Dusek, M., Mares, J.A., Mihokova, E., Nikl, M., 2000. Tunnelling process in thermally stimulated luminescence of mixed $\mathrm{Lu}_{x} \mathrm{Y}_{1-x} \mathrm{AlO}_{3}$ : Ce crystals. Phys. Rev. B 61, $8081-8086$

Vedda, A., Fassoli, M., Moretti, F., Mihokova, E., Nikl, M., Pejchal, J., Zorenko, Yu., Gorbenko, V., Blazek, K., Nejezchleb, K., 2006. Trap levels and recombination centers in LPE grown Ce-doped LuAG and YAG thin films. In: Gektin, A., Grinyov, B. (Eds.), Proceedings of SCINT2005., pp. 464-467.

Wojtowicz, A.J., Bruyndonckx, P., Drozdowski, W., Galazka, Z., Glodo, J., Lukasiewicz, T., Szupryczynski, P., Tavernier, S., Wisniewska, M., Wisniewski, D., 2002. Traps and recombination centers in $\mathrm{YAlO}_{3}$ : Ce, Co. NIMA 486, 482-485.

Zorenko, Y., Gorbenko, V., Konstankevych, I., Voloshinovskii, A., Stryganyuk, G., Mikhailin, V., Kolobanov, V., Spassky, D., 2005b. Single-crystalline films of Ce-doped YAG and LuAG phosphors: advantages over bulk crystals analogues. J. Lumin. 114, 85-94.

Zorenko, Y., Gorbenko, V., Mihokova, E., Nikl, M., Nejezchleb, K., Vedda, A., Kolobanov, V., Spassky, D., 2007b. Single crystalline film scintillators based on Ce- and Pr-doped aluminium garnets. Radiat. Meas. (2007), doi:10.1016/j.radmeas.2007.01.045.

Zorenko, Yu., Gorbenko, V., Konstankevych, I., Grinev, B., Globus, M., 2002. Scintillation properties of $\mathrm{Lu}_{3} \mathrm{Al}_{5} \mathrm{O}_{12}$ : Ce single crystalline films. NIMA 486, 309-314.

Zorenko, Yu., Voloshinovskii, A., Gorbenko, V., Zorenko, T., Nikl, M., Nejezchleb, K., 2007a. Intrinsic luminescence of $\mathrm{YAlO}_{3}$ perovskites, Phys. Status. Solidi (c) 4, 963-967.

Zorenko, Yu.V., Voloshinovskii, A.S., Stryganyuk, G.M., Konstankevych, I.V., 2004a. Ultraviolet luminescence of single crystals and single-crystal films of $\mathrm{YAlO}_{3}$. Opt. Spectros. 96, 70-76.

Zorenko, Yu.V., Voloshinovskii, A.S., Konstankevych, I.V., $2004 \mathrm{~b}$. Luminescence of $\mathrm{F}^{+}$and $\mathrm{F}$ centers in YAP. Opt. Spectros. 96, 532-537.

Zorenko, Yu.V., Voloshinovskii, A.S., Stryganyuk, G.M., Gorbenko, V.I., 2005a. Luminescence of excitons in single crystal and single-crystal films of $\mathrm{YAlO}_{3}$. Opt. Spectros. 98, 614-617. 